\title{
Healthy Lifestyle and Having Problems of Health of Individuals Living in A Neighbourhood of Karesi Country in Balıkesir
}

\author{
Balıkesir Karesi İlçesine Bağlı Bir Mahallede Yaşayan Kişilerin Sağlık Sorunu \\ Yaşama Durumları ve Sağlıklı Yaşam Biçimi Davranışları
}

\author{
Celalettin Çevik*1, Sibel Ergün ${ }^{1}$, Ibrahim Aldemir ${ }^{2}$, Saliha Şence ${ }^{3}$
}

\begin{abstract}
Aim: The aim of this study is to evaluate the illness and healthy lifestyle behaviours last 15 days among individuals who were 18 years old or above in an urban area in the city center of Balikesir province. Method: This cross-sectional study was applied face to face to individuals who were 18 years old or above living in an urban area in Balikesir city center. Population of this study consisted of individuals who were 18 years old or above living in Adnan Menderes neighbourhood. The sample of the study concluded 394 individuals considering $15 \%$ of frequency of having health problem, 5\% of type 1 error, 5\% of deviation and $2 \%$ design effect. The sample group was reached by multi stage cluster sampling. The survey comprised of the form of health service use and healthy lifestyle behaviours scale. Number and percentage, chi-square, Independent-Samples t test, the one-way analysis of variance and logistic regression was used to analyse the data. Results: $65 \%$ of the sample was female; $28 \%$ was in the group of $18-27$ years of age; $62 \%$ of participants had high school or higher level of education; $56 \%$ was married. $23 \%$ of participants had health problems last 15 days. $61,5 \%$ of those who had health problems went to hospital. Disease frequency for those who were illiterate, those who had broken family, and those who had chronic illness were found statistically significant ( $<<0,05$ ). The educational level of health problem was 0,2 times $(0,1-0,5)$ lower than those of illiterates in high school students, 5,4 times $(1,4-6,3)$ compared to those of the core family type in those of the extended family type, 15,3 times 2,8-8,4), 11,9 times $(6,32-12,62)$ higher than those without chronic disease, and 0,9 times $(0,9-0,9)$ health problems compared to those with lower levels of healthy lifestyle behaviours. Point average of healthy lifestyle behaviour scale was $136,7 \pm 20,2$ in research group. Scale point was statistically higher for individuals who live alone, those who go to physician regularly, those who generally go to public hospital, and those who get knowledge about health issues from internet $(\mathrm{p}<0,05)$. Conclusion: Healthy lifestyle behaviours were found to be higher in those with moderate or state hospital visits, regular physician controls. Among the participants, socioeconomically disadvantaged groups have a high incidence of health problems and low health-style behaviour scores. For this reason, the development of healthy lifestyle behaviours of disadvantaged groups may reduce the frequency of living with health problems.
\end{abstract}

Key words: Health Lifestyle, health problem, health promotion, prevention.

\section{ÖZET}

\begin{abstract}
Amaç: Bu çalışmada, kentsel bir bölgede yaşayan kişilerin, son 15 gün içinde sağlık sorunu yaşama durumlarının ve sağlıklı yaşam biçimi davranışlarının değerlendirilmesi amaçlanmıştır. Yöntem: Kesitsel tipteki bu araştırmanın evrenini, Balıkesir ili, Karesi ilçesi, Adnan Menderes Mahallesinde yaşayan, 18 yaş ve üzeri kişiler oluşturmaktadır. Örnek büyüklüğü, son 15 gün içinde sağlık sorunu yaşama sıklığı \%15, \%5 tip I hata, \%5 sapma, 2 desen etkisi göz önünde bulundurularak 394 kişiden oluşmaktadır. Örneklem grubuna, çok aşamalı küme örnekleme yöntemi ulaşılmıştır. Sağlık hizmet kullanımı formu ve sağlıklı yaşam biçimi davranışları ölçeği, yüz yüze görüşülerek uygulanmıştır. Çözümlemede, sayı ve yüzdeler ki-kare testi, t testi, tek yönlü varyans analizi ve lojistik regresyon analizi kullanılmıştır. Bulgular: Araştırma grubundaki kişilerin, \%65,5'i kadın, \%28,7'si 18-27 yaş grubunda, \%62,4'ü lise ve üzeri öğrenime sahip, \%56,6'sı evli kișilerdir. Katılımcıların \%23,1'inin son 15 gün içinde bir sağlık sorunu yașamıș, \%61,5'i sağlık kurumuna başvurmuștur. Okuryazar olmayanlarda, güvencesi olmayanlarda, parçalanmış aileye sahip kişilerde ve kronik hastalığı olan kişilerde sağlı sorunu yaşama sıklığı anlamlı olarak yüksek bulunmuștur $(\mathrm{p}<0,05)$. Sağlık sorunu yaşama durumu, eğitim durumu lise olanlarda, okuryazar olmayanlara kıyasla 0,2 kat $(0,1-0,5)$ düsük, geniş aile tipindeki kişilerde, çekirdek aile tipinde olanlara kıyasla 5,4 kat (1,4-6,3), parçalanmış aile tipinde olanlarda, çekirdek aile yapısına sahip olanlara göre 15,3 kat $(2,8-8,4)$ yüksek, kronik hastalığı olanlarda, olmayanlara kıyasla 11,9 kat $(6,3-12,6)$ yüksek, sağlıklı yaşam biçimi davranışları yüksek olanlarda,

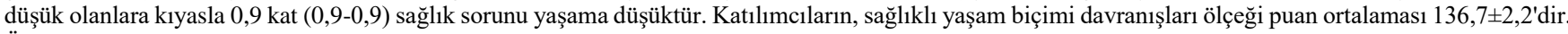
Ölçek puanı, yalnız yaşayanlarda, düzenli olarak hekime gidenlerde, genellikle devlet hastanesine başvuranlarda, sağlıkla ilgili bilgileri internetten edinenlerde anlamlı olarak yüksek bulunmuştur ( $\mathrm{p}<0,05)$. Sonuç: Sağlıklı yaşam biçimi davranışları puanı orta düzeyde olup, devlet hastanesine başvuran, düzenli hekim kontrolünde olan kişilerde yüksek bulunmuştur. Katılımcıların içinde sosyoekonomik olarak dezavantajlı olan gruplarda, sağlık sorunu yaşama sıklığı yüksek, sağlıklı yaşam biçimi davranış puanı yüksek kişilerde düşük bulunmuştur. Bu nedenle, dezavantajlı grupların sağlıklı yaşam biçimi davranışlarının geliştirilmesi, sağlık sorunu yaşama sıklı̆̆ını azaltabilir.
\end{abstract}

Anahtar kelimeler: Sağlıklı yaşam biçimi, sağlık sorunu yaşama, sağlı̆̆ı geliştirme, koruma

Received / Geliş tarihi: 27.11.2017, Accepted / Kabul tarihi: 08.04.2018

${ }^{1}$ Balıkesir Üniversitesi Balıkesir Sağlık Yüksekokulu, Hemșirelik Bölümü

${ }^{2}$ Maltepe Devlet Hastanesi, İstanbul

${ }^{3}$ Keșan Devlet Hastanesi, Edirne

*Address for Correspondence / Yazışma Adresi: Celalettin Çevik, Balıkesir Üniversitesi Balıkesir Sağlık Yüksekokulu, Hemşirelik Bölümü, Balıkesir TÜRKIYE, E-mail: celalettincevik@balikesir.edu.tr

Çevik C, Ergün S, Aldemir I, S Şence S. Balikesir Karesi İlçesine Bağlı Bir Mahallede Yaşayan Kişilerin Sağlık Sorunu Yaşama Durumları ve Sağlıklı

Yaşam Biçimi Davranışları. TJFMPC, 2018; 12 (2): 109- 116. DOI: 10.21763/tjfmpc.432535 


\section{GíRIŞ}

Çağdaş sağlık anlayışı, birey, aile ve toplumun sağlığını koruyan, geliştiren, bireyin kendi sağlığ1 üzerindeki kontrolünün kazandırılması üzerine kuruludur. ${ }^{1}$ Ottawa Sağlığı Geliştirme Konferansında ve Dünya Sağlık Örgütünün (DSÖ), 21. Yüzyılda Herkes İçin Sağlık hedeflerinde, sağlığ1 geliştirmenin önemi üzerinde durulmuş, sigara içme, alkol ve madde kullanımı, sağlıksız kilo alımı, fiziksel inaktivite, şiddet davranışları ve stres gibi sağlıksız davranışların azaltılması hedeflenmiştir. ${ }^{2}$ DSÖ projeksiyonlarına göre, toplumdaki erken ölümlerin ana nedenleri içinde ön sıralarda yer alan kardiyovasküler hastalıklar, kronik solunum yolu hastalıkları, kanserler ve diyabet için risk faktörleri olan tütün, alkol ve tuz kullanımının azaltılması, obezitenin, kan şekeri ve kan basıncının düşürülmesi ile, 2010-2025 arasında erken ölümler içinde erkeklerde \%22, kadınlarda \%19 azalma olacağ1 öngörülmektedir. $.3 \mathrm{Bu}$ nedenle, sağlığ1 destekleyen bir çevrenin oluşturulması, sağlık hizmetlerine yön verme ve buna göre sağlık politikası oluşturulması toplumun yaşam kalitesinin artırılması, sağlıklı yaşam biçimi davranışları kazanması bakımından önemlidir. Bireylerin, yaşam tarzını değerlendiren gereçlerden biri bireylerin sağlık sorumluluğu, fiziksel aktivite, beslenme, manevi gelişim, kişilerarası ilişkiler ve stres yönetimini ölçen sağlıklı yaşam biçimi davranışları ölçeğidir (SYBDÖ)..,$\underline{5}$ Literatüre bakıldığında, SYBDÖ puanının 107,8-137,5 olduğu görülmektedir. 6-11 SYBDÖ puanın, yaşa, $\frac{12-15}{6}$ eğitim durumuna, $, \underline{8}, \underline{12}, \underline{16}$ sosyal sinifa,,$\underline{6}$ medeni duruma, $, \underline{8}, \underline{12-}$ 15 kronik hastalığı olma durumuna, $\underline{8}$ göre değiştiği görülmektedir. Çalışmalar, yaşam biçimi ile sağlık sorunu yaşama ve sağlık hizmet kullanımı arasında ilişki olduğunu göstermektedir. Sağlıksız yaşam biçimi davranışlarına sahip olma durumunun, bireyin sağlığı üzerindeki etkilerinden biri de sağlık sorunu yaşama riskinin artmasıdır. SYBDÖ puanı düşük kişilerde, fiziksel aktivite, sağlıksız diyet ve stres yönetiminin iyi olmaması gibi başta kronik hastalıklar olmak üzere, sağlık sorunlarının ortaya çıktığı, ancak egzersiz, diyet, duygusal destek gibi hastalık risk faktörlerinin önlenebileceği görülmektedir. $\underline{17}, \underline{18}$

Sağlık sorunu yaşamanın önüne geçilmesinde, bireyin kendi sağlığına yönelik koruyucu ve sağlığı geliştirici davranışları ve davranış değişikliklerini gösterebilmesi, sağlık sorumluluğu alabilmesi önem taşımaktadır. Nitekim sağlıklı yaşam biçimi davranışlarına sahip kişilerde, yaşam kalitesinin, sağlık sorunu yaşam durumunun daha az olması beklenmektedir. 16-19 Literatürde sağlık sorunu yaşama sıklığı, son 15 gün, son 1 ay, son 3 ay olmak üzere, sorulan sağlı sorunu yaşama durumu literatürde son 15 gün için \%8,3-39,5 arasında değişmektedir. 9 , 11, 20-23 Literatürde, sağlık sorunu yaşama sıklığı konusunda saptanan farklılıklarda önemli düzeyde, toplumun yaş yapısı, $\underline{22}, \underline{24}, \underline{25}$ cinsiyet, $\underline{25}, \underline{26}$ kronik hastalı $\breve{g}_{1}$ olma, $\underline{20}, \underline{24}$ bilinen risk faktörlerindendir. Sağlığı korumada, geliştirmede, yaşam kalitesinin artırılmasında bireyin kendi sağlığını nasıl algıladığı, bedeninin farkında olması, sağlık sorunu yaşaması, sağlık hizmet kullanımı gibi kendisi ve sağlık sistemiyle ilgili koşullar belirleyici olmaktadır. $\underline{27}$ Literatürde, özellikle öğrenciler, hemşireler, hekimler, öğretmenler gibi izlenmesi kolay grupların sağlıklı yaşam biçimi davranışlarını belirlemeye yönelik çalışmalar olmasına karşın,,$\underline{6,15}$, 26 toplum tabanlı yürütülen çalışma sayısı oldukça azdır. $\underline{11}, \underline{23}$

Bu çalışmanın amacı, Balıkesir'de Karesi ilçesine bağlı bir mahallede yaşayan kişilerin, sağlıklı yaşam biçimi davranış puanları, sağlık sorunu yaşama durumları ve ilişkili faktörlerin belirlenmesidir.

\section{GEREÇ VE YÖNTEM}

Kesitsel tipteki bu çalışma, Balıkesir ilinde kentsel bir bölgede yaşayan, on sekiz yaş ve üzeri kişilerle, Ağustos-Eylül 2016 tarihleri arasında yüz yüze görüşülerek yürütülmüştür. Araştırmanın evrenini, Adnan Menderes Mahallesinde yaşayan 11008 kişi oluşturmaktadır. Araştırmanın örnek büyüklüğünü ise, son 15 günde sağlık sorunu yaşama sıklığ1 \%15, $\% 5$ tip I hata, \%5 sapma, 2 desen etkisi göz önünde bulundurularak 394 kişi oluşturmaktadır. Örnek grubuna çok aşamalı küme örnekleme yöntemi ile ulaşılmıştır. Muhtarlıktan, basit rastgele seçim yöntemiyle belirlenen 10 küme başı hane istenmiş, her bir kümeden otuz dokuz kişiye bir yönerge doğrultusunda ikişer hane atlanarak kümedeki kişi sayısı tamamlanmıştır.

Anket, sağlık hizmet kullanımı soru formu ve 1987 yılında Walker, Sechrist ve Pender tarafından sağlığı geliştirme modelini test etmek amacıyla geliştirilen, Esin ve ark. tarafından Türkçe geçerliliği güvenilirliği yapılan "SYBDÖ" kullanılmıştır. ${ }^{-}, \underline{5}$ Sağlık sorunu yaşama ve sağlıklı yaşam biçimi davranışları, araştırmanın bağımlı değişkenleri olup, yaş, cinsiyet, sağlık güvencesi, gelir durumu, çalışma durumu, aile tipi, kronik hastalık varlığı bağımsız değişkenlerdir. Sağlık hizmet kullanımı formunda, son 15 gün içinde sağlık sorunu yaşama, sağlık kurumuna başvurmaya yönelik sorular ve sağlıklı yaşam biçimi davranışları ölçeği ise bireyin sağlıklı yaşam biçimine yönelik sağlığı geliştiren davranışları ölçen sorulardan oluşmaktadır. Sağlıklı yaşam biçimi davranışları kendini gerçekleştirme, sağlık sorumluluğu, fiziksel aktivite, beslenme, kişilerarası ilişki ve stres yönetimi olmak üzere 6 alt boyutu olan ölçek, toplam 52 maddeden oluşan bir ölçektir. Araştırmada elde edilen veriler SPSS 22.0 
programında çözümlenmiştir. Çözümlemede, sayı ve yüzdeler, ki-kare testi, t testi, Tukey HSD'li tek yönlü varyans analizi ve lojistik regresyon analizi kullanılmıştır.

Araştırmanın yürütülmesi için, Balıkesir Valiliğinden yazılı izin alınmıştır (05/04/2016 tarih ve 96450617/044-6419 sayılı). Çalışmaya katılan bireylere, araştırmanın amacı ve katılımın gönüllük esasına bağlı olduğu anlatıldıktan sonra, istedikleri zaman araştırmadan çıkabilecekleri söylenmiştir. Gönüllülük ilkesine özen gösterilerek, katılımcıların sözel ve yazılı onamları alınmıştır.

\section{BULGULAR}

Araştırma grubunun yaş ortalaması $38,3 \pm 14,6$ olup, \%34,5'ini erkekler, \%62,4'ünü lise ve üzeri öğrenime sahip kişiler, \%56,6'sını evli, \%93,4'ünü ailesiyle birlikte yaşayan, \%89,1'ini sağlık güvencesi olan, \%85,8'ini geniş aile yapısına sahip kişiler, \%56,9'unu maddi durumunu yetersiz olan, $\% 59,6$ 'sını herhangi bir kronik hastalığı olmayan, \%33,3'ünü kronik hastalığı nedeniyle düzenli olarak hekim kontrolüne giden kişiler oluşturmaktadır (Tablo 1). Araştırma grubundaki kişilerin \%23,1'i son 15 gün içinde sağlık sorunu yaşamış, bunların \%61,5'i sağlık kurumuna başvurmuştur. Sağlık kurumuna başvuranların \%53,5'i devlet hastanesine gittiğini, \%39,3'ü sağlık sorunu yaşadıklarında genellikle devlet hastanesini tercih ettiğini, \%18,0'1 son 1 yıl içinde yatarak tanı tedavi aldığını, \%22,1'i evde bakım hizmeti aldığını, \%39,4'ü sağlıkla ilgili bilgileri internetten edindiğini \%56,6's1 toplumun sağlık konusunda farkındalığa sahip olmadığını bildirmiştir (Tablo 2).

Araştırma grubunda, son 15 gün içinde sağlık sorunu yaşama, yaş arttıkça artmaktadır. Okuryazar olmayanlarda, sağlık güvencesi olmayanlarda, parçalanmış aileye sahip kişilerde ve kronik hastalığı olan kişilerde sağlık sorunu yaşama durumu anlamlı olarak yüksektir $(\mathrm{p}<0,05)$. Cinsiyet, medeni durum, gelir durumuna göre son 15 gün içinde sağlı sorunu yaşama durumu benzerdir (p>0,05) (Tablo 3).

Araştırma grubunda, ölçek alt puanları, kendini gerçekleştirme boyutunda $26,4 \pm 4,6$, sağlık sorumluluğu alt boyutunda $22,5 \pm 4,4$, fiziksel aktivite alt boyutunda $18,2 \pm 4,6$, beslenme alt boyutunda $22,4 \pm 4,0$, kişiler arası ilişkiler alt boyutunda $25,6 \pm 4,4$, stres yönetimi alt boyutunda $21,4 \pm 4,2$, ölçek toplam puanı $136,7 \pm 20,2$ 'dır. Araştırma grubunda, yaş, cinsiyet, medeni durum, eğitim durumu, sağlık güvencesi olma durumu, maddi durum, son 15 gün içinde sağlık kurumuna başvurma, kronik hastalığı olma durumuna göre sağlıklı yaşam biçimi davranışları puan ortalaması benzerdir $(p>0,05)$. Yalnız yaşayanlarda, düzenli olarak hekime gidenlerde, son 15 gün içinde sağlık sorunu yaşamayanlarda, sağlıkla ilgili bilgileri internetten takip edenlerde sağlıklı yaşam biçimi davranışları puanı anlamlı olarak yüksektir $(\mathrm{p}<0,05)$ (Tablo 4).

Tablo 5'te sağlık sorunu yaşama durumu ve etkili faktörler, lojistik regresyon modeli ile değerlendirilmiştir. Sağlık sorunu yaşama durumu, eğitim durumu lise olanlarda, okuryazar olmayanlara kıyasla 0,2 kat $(0,1-0,5)$ düşük, geniş aile tipindeki kişilerde çekirdek aile tipinde olanlara kıyasla 5,4 kat (1,4-6,3), parçalanmış aile tipinde olanlarda, çekirdek aile yapısına sahip olanlara göre 15,37 kat $(2,83-18,41)$ yüksek, kronik hastalığı olanlarda, olmayanlara kıyasla 11,9 kat $(6,3-12,6)$ yüksek, sağlıklı yaşam biçimi davranışları yüksek olanlarda, düşük olanlara kıyasla 0,9 kat $(0,9-0,9)$ sağlık sorunu yaşama düşük bulunmuştur. Yaş ve sağlık güvencesi ile sağlık sorunu yaşama arasında ilişki bulunmamıştır.

Tablo 5'e bakıldığında, modelin $\left(\chi^{2}=114,696, \quad \mathrm{p}=0,001, \quad\right.$ Cox\&Snell $\quad \mathrm{R}^{2}=0,25$, Nagelkerke $\mathrm{R}^{2}=0,38$ ) anlamlı olduğu görülmektedir. Modelde yer alan yaş ve sağlık güvencesi dişında eğitim, aile tipi, kronik hastalık ve sağlıklı yaşam biçimi davranıșları puanı değişkenlerinin istatistiksel açıdan anlamlı olduğu söylenebilir. Modelin genel olarak doğru sinıflandırma oranı \%76,9'dur. $\mathrm{Bu}$ sonuçlara göre kurulan modelin geçerli ve kullanılabilir bir model olduğu görülmektedir.

\section{TARTISMA}

$\mathrm{Bu}$ çalışma, Balıkesir il merkezinde kentsel bir bölgede yürütülen, sağlık sorunu yaşama durumu ile SYBD ölçeğinin birlikte ele alındığı toplum tabanlı bir çalışmadır. Literatürde, daha çok öğrenciler, öğretmenler, sağlık çalışanları gibi gruplar üzerinde yürütülen çalışmalar olduğu için, $\underline{6}, \underline{8}, \underline{12}, \underline{14}$ bu durum karşılaştırmayı güçleştirmektedir. Araştırma grubunda SYBDÖ puanı orta düzeydedir $(136,7 \pm 20,2)$. Literatür incelendiğinde, SYBDÖ puanının öğrenciler, sağlık çalışanları, öğretmenler, hastalar gibi özel gruplarda 107,8-137,5 arasında değiştiği, $, \underline{6-8}, \underline{10}$ görülmektedir. Çalışmamızdaki SYBDÖ puanının, literatüre benzer olmakla birlikte birçoğundan yüksek olduğu görülmektedir. $\mathrm{Bu}$ farklılık bizim çalışmamızın toplum tabanlı olmasına bağlı olabilir. Nitekim literatürde sağlık çalışanlarında, düşük sosyoekonomik yapıya sahip gruplarda,,-6 SYBDÖ puanının düşük, öğretim elemanları ve kronik hastalık tanısı alanlarda yüksek bulunmuştur. 


\begin{tabular}{|l|l|r|r|}
\hline \multicolumn{3}{|l|}{ Tablo 1. Araştırma grubunun sosyodemografik özellikleri } \\
\hline Değişkenler & Erkek & Sayı & \% \\
\hline Cinsiyet & Kadın & 136 & 34,5 \\
& $18-27$ & 258 & 65,5 \\
\hline Yaş grubu & $28-37$ & 113 & 28,7 \\
& $3 \pm$ Ss: $38,3 \pm 14,6$ & 95 & 24,1 \\
& $48+47$ & 80 & 20,3 \\
\hline Eğitim durumu & Okuryazar değil & 106 & 26,9 \\
\hline & İlköğretim & 33 & 8,4 \\
& Lise ve üzeri & 115 & 29,2 \\
& Evli & 246 & 62,4 \\
\hline Medeni durum & Bekar & 223 & 56,6 \\
& Boşanmış & 138 & 35,0 \\
\hline Evde yaşanılan kişi & Ailesiyle & 33 & 8,4 \\
\hline Sağlık güvencesi & Yalnız & 366 & 92,9 \\
& Var & 28 & 7,1 \\
\hline Aile tipi & Yok & 351 & 89,1 \\
& Çekirdek & 43 & 10,9 \\
\hline Maddi durum & Geniş & 338 & 85,8 \\
& Parçalanmış & 37 & 9,4 \\
\hline Kronik hastalık & Yeterli & 19 & 4,8 \\
\hline Kronik hastalık izlemi için düzenli gidilen hekim & Yetersiz & 170 & 43,1 \\
& Var & 224 & 56,9 \\
\hline Toplam & Var & 159 & 40,4 \\
& Yok & 235 & 59,6 \\
\hline & & 53 & 33,3 \\
& & 106 & 66,7 \\
\hline
\end{tabular}

X: Ortalama, SS: Standart sapma

\begin{tabular}{|c|c|c|c|}
\hline \multicolumn{2}{|l|}{ Değişkenler } & Sayı & $\%$ \\
\hline Son 15 gün içinde sağlık sorunu & $\begin{array}{l}\text { Evet } \\
\text { Hayır }\end{array}$ & $\begin{array}{r}91 \\
303\end{array}$ & $\begin{array}{l}23,1 \\
76,9\end{array}$ \\
\hline $\begin{array}{l}\text { Bu sağlık sorunu olduğunda ne } \\
\text { yaptıniz? }\end{array}$ & $\begin{array}{l}\text { Hiçbir şey yapmadım } \\
\text { Kendi kendime tedavi etmeye çalıştım } \\
\text { Sağlık kurumuna gittim } \\
\text { Geleneksel sağlıkçılara gittim }\end{array}$ & $\begin{array}{r}22 \\
9 \\
56 \\
4\end{array}$ & $\begin{array}{r}24,2 \\
9,9 \\
61,5 \\
4,4 \\
\end{array}$ \\
\hline Tercih edilen sağlık kurumu & $\begin{array}{l}\text { Aile sağlığı merkezi } \\
\text { Devlet hastanesi } \\
\text { Üniversite hastanesi } \\
\text { Özel hastane }\end{array}$ & $\begin{array}{r}7 \\
30 \\
13 \\
21\end{array}$ & $\begin{array}{l}12,5 \\
53,5 \\
23,2 \\
10,7\end{array}$ \\
\hline $\begin{array}{lll}\text { Genellikle } & \text { gidilen } & \text { sağlık } \\
\text { kurumu } & & \end{array}$ & $\begin{array}{l}\text { Aile sağlığı merkezi } \\
\text { Devlet hastanesi } \\
\text { Üniversite hastanesi } \\
\text { Özel hastane }\end{array}$ & $\begin{array}{r}145 \\
155 \\
22 \\
72\end{array}$ & $\begin{array}{r}36,8 \\
39,3 \\
5,6 \\
18,3\end{array}$ \\
\hline $\begin{array}{l}\text { Son } 1 \text { yılda yatarak tanı ve } \\
\text { tedavi }\end{array}$ & $\begin{array}{l}\text { Evet } \\
\text { Hayır }\end{array}$ & $\begin{array}{r}71 \\
323 \\
\end{array}$ & $\begin{array}{l}18,0 \\
82,0\end{array}$ \\
\hline Evde bakım hizmeti alma & $\begin{array}{l}\text { Evet } \\
\text { Hayır }\end{array}$ & $\begin{array}{r}87 \\
307\end{array}$ & $\begin{array}{l}22,1 \\
77,9\end{array}$ \\
\hline Toplam & & 394 & $\overline{100,0}$ \\
\hline
\end{tabular}

Araştırma grubunun beşte biri, son 15 gün içinde sağlık sorunu yaşamıştır. Literatürdeki çalışmalara göre, son 15 günde sağlık sorunu yaşama $\% 8,3-39,5$ arasında değiştiği görülmektedir. ., 11, 21-24 Sağlık sorunu yaşama siklığındaki bu farklılık, sağlık algısı, araştırma yöntemi ve gelişmişlik düzeyine bağlı olabilir. Nitekim refah düzeyi daha yüksek olanlarda ve sağlık sigortası sistemi kapsamında olanlarda, diğer gruplara göre daha önemsiz sorunların sağlık sorunu olarak algılandığı 


\begin{tabular}{|c|c|c|c|c|c|c|c|c|c|}
\hline \multirow{3}{*}{\multicolumn{2}{|c|}{ Değişkenler $(n=394)$}} & \multicolumn{6}{|c|}{ Son 15 gün içinde sağlık sorunu yaşama } & \multirow{3}{*}{$\chi^{2}$} & \multirow{3}{*}{$\mathbf{p}$} \\
\hline & & \multicolumn{2}{|c|}{ Var } & \multicolumn{2}{|c|}{ Yok } & \multicolumn{2}{|c|}{ Toplam } & & \\
\hline & & Sayı & $\%$ & Sayı & $\%$ & Sayı & $\%$ & & \\
\hline \multirow[t]{4}{*}{ Yaş } & 18-27 yaş & 10 & 8,8 & 93 & 91,2 & 113 & 100,0 & \multirow{4}{*}{12,110} & \multirow{4}{*}{$\mathbf{0 , 0 2 0}$} \\
\hline & $28-37$ yaş & 12 & 12,6 & 83 & 87,4 & 95 & 100,0 & & \\
\hline & $38-47$ yaş & 27 & 33,8 & 53 & 66,2 & 80 & 100,0 & & \\
\hline & 48 ve üzeri yaş & 55 & 51,9 & 51 & 48,1 & 106 & 100,0 & & \\
\hline \multirow[t]{3}{*}{ Ĕ̆itim } & Okuryazar değil & 15 & 45,5 & 18 & 54,5 & 33 & 100,0 & \multirow{3}{*}{12,127} & \multirow{3}{*}{$\mathbf{0 , 0 0 4}$} \\
\hline & İlköğretim & 29 & 25,2 & 86 & 74,8 & 115 & 100,0 & & \\
\hline & Lise ve üzeri & 47 & 19,1 & 199 & 80,9 & 246 & 100,0 & & \\
\hline \multirow{2}{*}{$\begin{array}{l}\text { Sağlık } \\
\text { güvencesi }\end{array}$} & Yok & 15 & 34,9 & 28 & 65,1 & 43 & 100,0 & \multirow[b]{2}{*}{3,980} & \multirow[b]{2}{*}{$\mathbf{0 , 0 4 5}$} \\
\hline & Var & 76 & 21,7 & 275 & 78,3 & 351 & 100,0 & & \\
\hline \multirow[t]{3}{*}{ Aile tipi } & Çekirdek & 3 & 8,1 & 34 & 91,9 & 37 & 100,0 & \multirow{3}{*}{14,827} & \multirow{3}{*}{0,001} \\
\hline & Geniş & 75 & 22,4 & 260 & 77,6 & 335 & 100,0 & & \\
\hline & Parçalanmış & 10 & 52,6 & 9 & 47,4 & 19 & 100,0 & & \\
\hline \multirow{2}{*}{$\begin{array}{l}\text { Kronik } \\
\text { hastalık }\end{array}$} & Var & 72 & 45,3 & 87 & 54,7 & 159 & 100,0 & \multirow[b]{2}{*}{73,878} & \multirow[b]{2}{*}{0,001} \\
\hline & Yok & 19 & 8,1 & 216 & 91,9 & 235 & 100,0 & & \\
\hline
\end{tabular}

\begin{tabular}{|c|c|c|c|c|c|}
\hline \multirow{2}{*}{\multicolumn{2}{|c|}{ Değişkenler (n=394) }} & \multicolumn{2}{|c|}{$\begin{array}{l}\text { Sağlıklı yaşam biçimi } \\
\text { davranışları }\end{array}$} & \multirow{3}{*}{$\begin{array}{c}\begin{array}{c}\text { Test } \\
\text { değeri }\end{array} \\
t=2,447\end{array}$} & \multirow{3}{*}{$\begin{array}{c}\mathbf{p} \\
\mathbf{0 , 0 3 2}\end{array}$} \\
\hline & & Sayı & $\mathbf{X} \pm \mathbf{S s}$ & & \\
\hline Evde yaşanılan kişi & $\begin{array}{l}\text { Ailesiyle } \\
\text { Yalnız }\end{array}$ & $\begin{array}{l}366 \\
28\end{array}$ & $\begin{array}{l}133,7 \pm 18,6 \\
136,9 \pm 20,4\end{array}$ & & \\
\hline $\begin{array}{l}\text { Kronik hastalık izlemi için düzenli } \\
\text { gidilen hekim }\end{array}$ & $\begin{array}{l}\text { Var } \\
\text { Yok }\end{array}$ & $\begin{array}{c}53 \\
106\end{array}$ & $\begin{array}{l}142,0 \pm 16,9 \\
136,6 \pm 19,6\end{array}$ & $\mathrm{t}=2,147$ & $\mathbf{0 , 0 4 5}$ \\
\hline Son 15 gün içinde sağlık sorunu yaşama & $\begin{array}{l}\text { Evet } \\
\text { Hayır }\end{array}$ & $\begin{array}{c}91 \\
303 \\
\end{array}$ & $\begin{array}{l}134,9 \pm 20,6 \\
142,9 \pm 17,3 \\
\end{array}$ & $\mathrm{t}=3,379$ & $\mathbf{0 , 0 0 1}$ \\
\hline $\begin{array}{l}\text { Son } 15 \text { gün içinde sağlık kurumuna } \\
\text { başvurma }\end{array}$ & $\begin{array}{l}\text { Evet } \\
\text { Hayır }\end{array}$ & $\begin{array}{l}56 \\
35\end{array}$ & $\begin{array}{l}143,3 \pm 16,8 \\
142,4 \pm 18,2\end{array}$ & $\mathrm{t}=1,926$ & 0,057 \\
\hline Sağlık bilgisi edinilen kaynak & $\begin{array}{l}\text { İnternet } \\
\text { Sağlık çalışanları } \\
\text { TV'den } \\
\text { Takip etmiyorum }\end{array}$ & $\begin{array}{c}155 \\
45 \\
103 \\
91\end{array}$ & $\begin{array}{l}143,5 \pm 16,3 \\
129,0 \pm 20,6 \\
136,7 \pm 20,8 \\
133,0 \pm 20,8\end{array}$ & $\mathrm{~F}=7,437$ & $\mathbf{0 , 0 0 1}$ \\
\hline
\end{tabular}

X: Ortalama, Ss: Standart sapma, t=Student's t testi, F=Tukey HSD'li Tek Yönlü Varyans Analizi

\begin{tabular}{|c|c|c|c|c|c|c|}
\hline \multicolumn{2}{|l|}{ Değişkenler } & Beta & SH & $\mathbf{p}$ & OR & \%95 Güven Aralığı \\
\hline \multicolumn{2}{|l|}{ Yaş } & $-0,007$ & 0,010 & 0,525 & 0,98 & $0,97-1,01$ \\
\hline \multicolumn{2}{|c|}{ Sağlıklı yaşam biçimi davranış puanı } & $-0,027$ & 0,008 & 0,001 & 0,97 & $0,95-0,98$ \\
\hline Ĕgitim & $\begin{array}{l}\text { Okuryazar değil } \\
\text { İlköğretim } \\
\text { Lise ve üzeri }\end{array}$ & $\begin{array}{l}-0,542 \\
-1,473\end{array}$ & $\begin{array}{l}0,511 \\
0,483\end{array}$ & $\begin{array}{l}0,289 \\
\mathbf{0 , 0 0 2}\end{array}$ & $\begin{array}{l}0,59 \\
0,22\end{array}$ & $\begin{array}{c}1,0 \\
0,21-1,58 \\
0,09-0,59\end{array}$ \\
\hline Sağlık güvencesi & $\begin{array}{l}\text { Yok } \\
\text { Var } \\
\end{array}$ & 0,413 & 0,412 & 0,316 & 1,52 & $\begin{array}{c}1,0 \\
0,67-3,39 \\
\end{array}$ \\
\hline Aile tipi & \begin{tabular}{|l|} 
Çekirdek \\
Geniş \\
Parçalanmış
\end{tabular} & $\begin{array}{l}1,695 \\
2,733\end{array}$ & $\begin{array}{l}0,672 \\
0,863\end{array}$ & $\begin{array}{l}\mathbf{0 , 0 1 2} \\
\mathbf{0 , 0 0 2}\end{array}$ & $\begin{array}{c}5,44 \\
15,37\end{array}$ & $\begin{array}{c}1,0 \\
1,46-6,30 \\
2,83-18,41\end{array}$ \\
\hline Kronik hastalık & \begin{tabular}{|l|} 
Yok \\
Var
\end{tabular} & 2,481 & 0,325 & 0,001 & 11,95 & $\begin{array}{c}1,0 \\
6,32-12,62\end{array}$ \\
\hline
\end{tabular}

OR: Odds Ratio, $\mathrm{SH}=$ Standart Hata Cox and Snell $\mathrm{R}^{2}: 0,25 \quad$ Nagelkerke $\mathrm{R}^{2}: 0,38 \quad \chi^{2}: 114,696 \quad \mathrm{p}=0,001$ 
veya ifade edildiği görülmektedir. $\underline{9}, \underline{11}, \underline{21}, \underline{27}$ Ulusal ve uluslararası çalışmalara bakıldığında, bizim saptadığımız oran ortalama bir orandır. Literatürdeki farklılık, araştırma gruplarının sosyodemografik özelliklerinin yanı sıra, çalışmaların yöntem farklılıklarından da kaynaklanmaktadır. Manisa'da 2009 yılında yürütülen toplum tabanlı çalışmada, sağlık sorunu yaşama sıklığı bizim çalışmamızın yarısıdır. $\underline{20} \mathrm{Bu}$ durum, araştırma grubunun bizim çalışmamıza göre daha genç olmasına bağlı olabilir. İzmir'de yürütülen bir çalışmada, bizim çalışmamızdan yüksek biçimde kişilerin üçte biri, sağlık sorunu yaşamaktadır $\stackrel{24}{2}$. Bursa'da yürütülen çalışmada, her üç kişiden biri son 15 gün içinde hastalanmıştır 22 . İzmir ve Bursa'da yürütülen çalışmalarda, sağlık sorunu yaşama oranın bizim çalışmamızdan yüksek olması, Balıkesir'in gelişmişlik durumunun diğer illerden düşük olmasına bağlı olduğu düşünülmektedirr25. Gana'da yürütülen çalışmada, sağlık sorunu yaşama oranı, bizim çalışmamızdan düşük olması, Gana'daki çalışmada araştırma grubunun daha genç bir popülasyon üzerinde yürütülmesine bağlı olabilir $\underline{23}$. Çin'de yürütülen küçük ölçekli bir bölgedeki göçmenlerde yapılan çalışmada, sağlık sorunu yaşama durumu bizim çalışmamızın yarısıdırı1. $\mathrm{Bu}$ durum, sağlıklı göçmen etkisine, göçmenlerin sağlık algısının düşük olmasına ya da sağlık güvencesi olmamasına bağlı olduğu düşünülmektedir. Myanmar'da yürütülen bir çalışmada da, sağlık sorunu yaşama sıklığı bizim çalışmamızın yarısıdır. ${ }^{26} \mathrm{Bu}$ fark, Myanmar' daki çalışmanın düşük sosyoekonomik özelliklere sahip bir grupta yürütülmesine bağlı olabilir. Çin'de yürütülen toplum tabanlı bir çalışmada ise, bizim çalışmamıza benzer biçimde her beş kişiden biri son 15 gün içinde sağlık sorunu yaşamıştır. $\underline{28}$

Araştırma grubunda, SYBDÖ puanını etkileyen değişkenlere bakıldığında, yaş, cinsiyet, medeni durum, eğitim durumu, sağlık güvencesi olma durumu, gelir durumu, kronik hastalığı olma durumuna göre sağlıklı yaşam biçimi davranışları puan ortalaması benzer olduğu bulunmuştur. Literatüre bakıldığında, yaş kimi çalışmalarda anlamlı bir fark oluşturmazken, $\underline{13}$ kimi çalışmalarda ise ileri yaş grubunda SYBDÖ puanı anlamlı olarak yüksektir. $\underline{6}, \underline{12}, \underline{14} \mathrm{Bu}$ farklılık, araştırma gruplarının yaş yapısının farklılığından, yaş arttıkça kronik hastalıklara bağlı olarak da bireylerin sağlıklı yaşam biçimi davranışlarına yöneliyor olmalarından kaynaklanabilir. Cinsiyet, bizim araştırmamızda anlamlı bir fark oluşturmayıp, benzer şekilde literatürdeki çalışmalarda da cinsiyete göre anlamlı fark saptanmamıştır. $\underline{10}, \underline{14}, \underline{15}$ Bizim çalışmamızdan farklı olarak, sosyoekonomik bakımdan farklı olan iki bölgede yürütülen bir çalışmada, erkeklerde SYBDÖ puanı yüksek bulunmuştur. ${ }^{6} \mathrm{Bu}$ durum, Konya'da yürütülen çalışmanın sosyoekonomik bakımdan daha heterojen olmasına ve daha çok kadınlara ulaşılmasına bağlı olabilir. Nitekim çalışan erkeklere ulaşılamamış, ileri yaş grubunda yaşam tarzına dikkat eden erkeklere ulaşılmış olabilir. Araştırma grubunda, eğitim durumuna göre SYBDÖ puanı literatürle benzer biçimde anlamlı fark oluşturmazken $\underline{13}$, 15 , bazı çalışmalarda eğitim durumu iyileştikçe SYBDÖ puanının arttığı görülmektedir.. , $\underline{12}, \underline{16}, \underline{29} \mathrm{Bu}$ çalışmaların, daha çok kadın popülasyon ağırlıklı olduğu düşünüldüğünde, eğitimleşme oranının bizim çalışmamıza göre daha düşük olması, kadınları alt sosyal sınıfta yer almasina neden olabilmektedir. Alt sosyal sınıftaki kadınların da yaşam tarzı olarak, üst sosyal sınıfa göre bağımlılıkları daha fazladır ${ }^{6}$. Araştırma grubunda medeni durum SYBDÖ puanının literatüre benzer biçimde medeni durumun etkisinin olmadığ 1 bulunmuştur.. , $\underline{12-15}$ Çalışmamızda, Konya'da yürütülen bir çalışmaya benzer biçimde, yalnız başına yaşayanlarda SYBDÖ puanı anlamlı olarak yüksek bulunmuştur. $\underline{6}$ Araştırmada, sağlık güvencesi olma durumuna göre İran'da yürütülen bir çalışmayla benzer biçimde, ölçek puanları arasında anlamlı fark yokken, bazı çalışmalarda da sağlık güvencesi olanlarda SYBDÖ puanı anlamlı olarak yüksek bulunmuştur. $\underline{26}$ Araştırma grubunda, gelir durumu SYBDÖ literatürle benzer olarak farklılık göstermezken, $\underline{14}, \underline{15}, \underline{29}$ bizim çalışmamızdan farklı olarak, iki farklı bölgede kadınlarla yürütülen bir çalışmada, $\underline{6}$ tıp fakültesi öğrencileriyle yürütülen bir çalışmada, $\underline{10}$ ve gebelerle yürütülen bir çalışmada, $\underline{16}$ gelir durumu algısı yüksek olanlarda SYBDÖ puanı anlamlı olarak yüksektir. Çalışmamızda, düzenli gidilen bir hekimi olan kişilerde, SYBDÖ puanı anlamlı olarak yüksek bulunmuştur. Bu durum daha çok birinci basamak hekimlere giden kişilerin sürekli hizmet kapsamında, aynı hekimden hizmet almalarının olumlu bir etkisi olarak görülebilir. Nitekim sağlık çalışanlarının nüfusunu tanıması sağlık davranışı oluşturma da önemli faktörlerden biridir.

Araştırma grubunda, son 15 gün içinde sağlık sorunu yaşama çok değişkenli regresyon modeline göre eğitim durumu yüksek kişilerde, çekirdek aile yapısına sahip kişilerde, SYBDÖ puanı yüksek kişilerde anlamlı olarak düşük, kronik hastalığ1 olanlarda yüksek bulunmuştur. Çalışmamızda ileri yaş grubunda hastalanma durumu literatürle benzer biçimde yüksek bulunmuştur. 22, 24, 25 Bizim çalışmamızda, cinsiyete göre sağlık sorunu yaşama bakımından anlamlı fark yok iken, Manisa'da, Bursa'da ve Myanmar'da yürütülen çalışmalar da kadınlarda sağlık sorunu yaşama durumu daha yüksek bulunmuştur. $\underline{20}, \underline{22}, \underline{26}$ Okuryazar olmayanlarda sağlık sorunu yaşama durumu, Bursa'da yürütülen çalışmaya benzer biçimde yüksektir. ${ }^{22}$ Çalışma sonuçlarımız ve literatür bulguları, sağlık sorunu yaşamada, kronik hastalığ1 olma, aile tipi, eğitim durumu ve SYBDÖ puanı belirleyici olduğunu göstermektedir. Nitekim 
çok değişkenli regresyon analizine göre de kronik hastalığ 1 olma, aile tipi, eğitim durumu ve SYBDÖ puanı sağlı sorunu yaşama durumunun \%36'sını açıklamaktadır. Çalışmamızda, sağlık sorunu yaşama, parçalanmış ailesi olanlarda daha yüksektir. Burada yalnız yaşamanın psikososyal sorunlara gebe olması etkili olabilir. Kronik hastalık olanlarda, sağlık sorunu yaşama durumu literatürdeki çalışmalarda da yüksek bulunmuştur. Manisa'da, İzmir'de yürütülen çalışmalarda benzer olarak kronik hastalığı olan kişilerde, sağlık sorunu yaşam durumu yüksektir. $\underline{20}, \underline{24}$, $\underline{25}$ Nitekim Lee ve ark. yürüttüğü sistematik derlemede de, benzer biçimde kronik hastalıklarda sağlık sorunu yaşama ve sağlık kurumuna başvurma durumu yüksek bulunmuştur. 9 Çalışmamızda, cinsiyet, medeni durum, gelir durumuna göre son 15 gün içinde sağlık sorunu yaşama benzerdir. Myanmar'da, Çin'de yürütülen çalışmalarda da bu durum benzerdir. $\underline{26}, \underline{28}$

$\mathrm{Bu}$ çalışmada, kişilerin SYBDÖ puanı düşük kişilerin daha çok sağlık sorunu yaşadığ1 bulunmuştur. Literatürle kıyaslandığında, SYBDÖ ve sağlık sorunu yaşamanın değerlendirilmesinden ziyade sigara içme, alkol kullanma, fiziksel aktivite yapma gibi davranışların sorgulandığı çalışmalar vardır. $\mathrm{Bu}$ çalışmalara göre olumsuz sağlık davranışına sahip gruplarda sağlık sorunu yaşama durumu yüksek bulunmuştur. $\underline{20}$ Bireyin kendi sağlığından sorumlu olması, sağlıklı yaşam tarzı benimsemesi sağlık sorunu yaşama sıklığını da azaltmaktadir $\underline{5}, \underline{16}, \underline{18}$. Nitekim Phiri ve ark. hemşirelerle yürüttüğü çalışmada da, çalışmamızla benzer biçimde sağlıksız davranışlara sahip kişilerin sağllk sorunu yaşama risklerinin yüksek olduğu bulunmuştur $\underline{18}$.

\section{SONUÇ ve ÖNERILLER}

Araştırma gurubunun SYBDÖ puanı orta düzeydedir. Yalnız yaşayanlarda, düzenli olarak hekime gidenlerde, son 15 gün içinde sağlık sorunu yaşamayanlarda, sağlıkla ilgili bilgileri internetten takip edenlerde sağlıklı yaşam biçimi davranışları puanı anlamlı olarak yüksektir.

Katılımcıların dörtte biri son on beş gün içinde sağlık sorunu yaşamıştır. Sağlık sorunu yaşama durumu, eğitim durumu düşük kişilerde, parçalanmış aile yapısında olan kişilerde ve SYBDÖ puanı düşük kişilerde yüksek bulunmuştur. Sağlık sorunu yaşama durumu üzerinde etkili olan öz sorumluluğun artırılması, sağlıklı yaşam tarzı değişikliklerinin sağlanması bireyin, toplumun korumaya geliştirmeye önemli katkı sağlayabilir. Katılımcıların sürekli aynı hekim tarafından izlenmesi SYBDÖ puanını artırdığından aynı hekimden hizmet alınmasının sağlanması, birinci basamak sağlık hizmetlerinin kapsayıcılı̆̆ının ve sürekliliğinin arttırılması önemlidir. Kişilerin
SYBDÖ puanı orta düzeyde olup, bu anlamda kişilere yönelik eğitimler verilmesi, bilgiye doğru kaynaktan ulaşılması sağlanabilir. Bireyin, ailenin toplumun sağlığını geliştirmede yaşam tarzının yanında çevresel düzenlemeler yapılması ve mevzuatın düzenlenmesi toplumun farkındalığını artırabilir.

\section{Çalışmanın Güçlü Yönleri ve Kısıtlılıkları}

Literatüre bakıldığında, sağlık sorunu yaşama durumu ve hizmet kullanımına yönelik farklı popülasyonlarda çalışmalar yürütülse de sağlıklı yaşam biçimi davranışlarının yürütüldüğü çalışmalar, genellikle öğrenciler, öğretmenler, sağlık çalışanları gibi incelemesi kolay olan gruplar üzerinde yapılmıştır. Bu nedenlerle, çalışmamızın toplum tabanlı olması güçlü yanı olmakla birlikte, literatürle kıyaslanması sınırlı olmuştur. Ayrıca çalışmamız kesitsel tipte olduğu için, neden ve sonuçlar aynı anda görüldüğünden nedensellik bağıntısı kurmak güç olmuştur. Çalışmanın mesai saatleri içinde yürütülmesi nedeniyle, hanelerde daha çok kadınlara ulaşılması araştırmamızın bir başka kısıtlılığıdır.

Bu çalışma 11-12 Kasım 2016 tarihinde İzmir'de düzenlenen 5. Sağlıkta Yaşam Kalitesi Kongresinde sözlü sunum olarak sunulmuştur.

\section{KAYNAKLAR}

1. Davies SC, Winpenny E, Ball S, Fowler T, Rubin J, Nolte E. For debate: a new wave in public health improvement. The Lancet. 2014;384(9957):1889-95.

2. Flynn MA. Empowering people to be healthier: public health nutrition through the Ottawa Charter. Proceedings of the Nutrition Society. 2015;74(3):303-12.

3. Kontis V, Mathers CD, Rehm J, Stevens GA, Shield KD, Bonita R, et al. Contribution of six risk factors to achieving the $25 \times 25$ noncommunicable disease mortality reduction target: a modelling study. The Lancet. 2014;384(9941):427-37.

4. Esin N. Sağlıklı yaşam biçimi davranışları ölçeğinin Türkçeye uyarlanması. Hemşirelik Bülteni. 1999;12(45):87-95.

5. Walker SN, Sechrist KR, Pender NJ. The health-promoting lifestyle profile: development and psychometric characteristics. Nursing research. 1987;36(2):76-81.

6. Koçoğlu D, Akın B. Sosyoekonomik eşitsizliklerin sağlıklı yaşam biçimi davranışları ve yaşam kalitesi ile ilişkisi. DEUHYO Dergisi. 2009;2(4):145-54.

7. Benemei S, De Cesaris F, Fusi C, Rossi E, Lupi C, Geppetti P. TRPA1 and other TRP channels in migraine. The journal of headache and pain. 2013;14(1):71. 
8. Sonmezer H, Cetinkaya F, Nacar M. Healthy life-style promoting behaviour in Turkish women aged 18-64. Asian Pac J Cancer Prev. 2012;13(4):1241-5.

9. Lee JT, Hamid F, Pati S, Atun R, Millett C. Impact of noncommunicable disease multimorbidity on healthcare utilisation and out-of-pocket expenditures in middle-income countries: cross sectional analysis. PLoS One. 2015;10(7):e0127199.

10. Şimşek H, Öztoprak D, İkizoğlu E, Safalı F, Yavuz Ö, Onur Ö, et al. Tip fakültesi öğrencilerinde sağlıklı yaşam biçimi davranışları ve ilişkili etmenler. Dokuz Eylül Üniversitesi Tıp Fakültesi Dergisi. 2012;26(3):151-7.

11. Zou G, Zeng Z, Chen W, Ling L. Self-reported illnesses and service utilisation among migrants working in small-to medium sized enterprises in Guangdong, China. Public health. 2015;129(7):970-8

12. Enjezab B, Farajzadegan Z, Taleghani F, Aflatoonian A, Morowatisharifabad MA. Health promoting behaviors in a populationbased sample of middle-aged women and its relevant factors in Yazd, Iran. International journal of preventive medicine. 2012;3(Suppl1):S191.

13. Özçelik H, Sönmez Y. Isparta il merkezinde görev yapan toplum lideri bazı meslek gruplarının sağlıklı yaşam biçimi davranışlarının değerlendirilmesi. Süleyman Demirel Üniversitesi Tıp Fakültesi Dergisi. 2015;22(4):115-25.

14. Ozvurmaz S, Mandiracioglu A. Healthy lifestyle behavior of employees in small and medium-sized enterprises in Aydin, Turkey. Pakistan journal of medical sciences. 2017;33(2):404.

15. Ulutasdemir N, Kilic M, Zeki Ö, Begendi F. Effects of occupational health and safety on healthy lifestyle behaviors of workers employed in a private company in Turkey. Annals of global health. 2015;81(4):503-11.

16. Onat G, Aba YA. Health-promoting lifestyles and related factors among pregnant women. Turkish Journal of Public Health. 2014;12(2):69.

17. Motaghi M, Dolatabadi ED. Lifestyle of elderly people of Isfahan's villages in Iran in 2014. International Journal of Humanities and Cultural Studies (IJHCS) ISSN 2356-5926. 2016:790-803.

18. Phiri LP, Draper CE, Lambert EV, KolbeAlexander TL. Nurses' lifestyle behaviours, health priorities and barriers to living a healthy lifestyle: a qualitative descriptive study. BMC nursing. 2014;13(1):38.

19. Semnani S, Noorafkan Z, Aryaie M, Sedaghat SM, Moghaddami A, Kazemnejhad V, et al. Determinants of healthcare utilisation and predictors of outcome in colorectal cancer patients from Northern Iran. European journal of cancer care. 2015.

20. Çevik C. Manisa kent merkezinde yaşayan kişilerde ayakta tanı ve tedavi hizmeti kullanımı ve etkili faktörlerin belirlenmesi. Manisa: Manisa Celal Bayar Üniversitesi; 2010.

21. Riaz A, Greer J, Murray L. Overview Report Office for National Statistics,. 2006:2-5.

22. Seçkin R. Nilüfer HSEAB'nde yaşayanların ayaktan tanı-tedavi ve koruyucu sağlık hizmetlerini kullanımları ve etkileyen etmenler [Uzmanlık Tezi]. Bursa: Uludağ Üniversitesi; 2009.

23. Frank A, Benedict AO, Adusei-Nkrumah J. Analysis Of Gender And Healthcare Services Utilization In Rural Ghana. Research journali's Journal of Public Health. 2016;2(2).

24. Aksakoğlu G, Uçku R, Okuyan Z, Ergör G, Günay T, Ergör A, et al. İzmir ili "Metropolitan" alanda toplumun sağlı düzeyi ve sağlık hizmetlerinin kullanımı. Toplum ve Hekim Dergisi. 2009;24:226-33.

25. Nesanır N, Dinç Horasan G, Cambaz S, Baysan P, Şerifhan M, Deveci S, et al. Sosyal Sinıfin ve Sağlık Güvencesinin Manisa'daki Sağlık Hizmet Kullanımı Üzerine Etkisi: Bir Eşitsizlik Araștırması. Turkiye Klinikleri Journal of Medical Sciences. 2010;30(4):1263-71.

26. SoeAung M, MyintOo W, ThiLwin K, Maung TM. Health Services Utilization and SelfReported Acute Illnesses among Urban Families Inthanlyin Township, Yangon Region, Myanmar. International Journal of Health Sciences and Research (IJHSR). 2016;6(1):3642.

27. Alvarez-Dardet C, Morgan A, Cantero MTR, Hernán M. Improving the evidence base on public health assets - the way ahead: a proposed research agenda. J Epidemiol Community Health. 2015:jech-2014-205096.

28. Ministry of Health China CfHSaI. Reports on the 2008 national health services survey results. 2009:131-40.

29. Özpulat F, Sivri BB. Birinci basamak sağlık hizmetlerine başvuran 55 yaş ve üstü kadınların sağlıklı yaşam biçimi davranışları. STED. 2013;22(3):80-9. 